\title{
Couples Coping with Congestive Heart Failure: \\ Role and Gender Differences in Psychological Distress
}

Michael J. Rohrbaugh, James A. Cranford, Varda Shoham,

John M. Nicklas, John S. Sonnega, and James C. Coyne

\begin{abstract}
Psychological distress and marital quality were assessed with male $(\underline{n}=128)$ and female $(\underline{n}=49)$ congestive-heart-failure patients and their spouses. Hopkins Symptom Check List-25 scores were in the distressed range for $57 \%$ of patients and $40 \%$ of spouses. This role difference was greater for men than women, and a gender difference (more distress in women than men) was greater for spouses than patients. The patient's distress, but not the spouse's, reflected the severity of the patient's illness, and distress for both partners correlated negatively with ratings of marital quality. Female-patient couples reported better relationship quality than male-patient couples, however, and a mediation analysis indicated that the gender difference in spouse distress could be explained by marital quality. Results highlight the contextual nature of CHF distress and suggest that role differences in distress vary by gender.
\end{abstract}

\section{Reference:}

Rohrbaugh, M.J., Cranford, J.A., Shoham, V., Nicklas, J.M., Sonnega, J. \& Coyne, J.C. (2002). Couples coping with congestive heart failure: Role and gender differences in psychological distress. Journal of Family Psychology, 16, 3-13. 